\title{
Actualities in immunological markers and electrochemical sensors for determination of dopamine and its metabolites in psychotic disorders (Review)
}

\author{
ADELA MAGDALENA CIOBANU ${ }^{1,2}$, LUANA GEZA $^{1,2}$, IULIA GABRIELA DAVID ${ }^{3}$, DANA ELENA POPA ${ }^{3}$, \\ MIHAELA BULEANDRA ${ }^{3}$, ANTON ALEXANDRU CIUCU $^{3}$ and LIANA DEHELEAN ${ }^{4}$ \\ ${ }^{1}$ Department of Psychiatry, 'Prof. Dr. Alexandru Obregia' Clinical Psychiatric Hospital, 041914 Bucharest; ${ }^{2}$ Discipline of \\ Psychiatry, Neurosciences Department, 'Carol Davila' University of Medicine and Pharmacy, 020021 Bucharest; \\ ${ }^{3}$ Department of Analytical Chemistry, Faculty of Chemistry, University of Bucharest, 050663 Bucharest; \\ ${ }^{4}$ Department of Neurosciences-Psychiatry, Centre for Cognitive Research in Neuropsychiatric Pathology, \\ 'Victor Babes' University of Medicine and Pharmacy of Timisoara, 300041 Timisoara, Romania
}

Received April 27, 2021; Accepted May 26, 2021

DOI: $10.3892 /$ etm.2021.10320

\begin{abstract}
Psychotic disorders represent a serious health concern. At this moment, anamnestic data, international criteria for diagnosis/classification from the Diagnostic and Statistical Manual of Mental Disorders-5 and the International Classification of Diseases-10 and diagnostic scales are used to establish a diagnosis. The most commonly used biomarkers in psychotic illnesses are those regarding the neuroimmune system, metabolic abnormalities, neurotrophins and neurotransmitter systems and proteomics. A current issue faced by clinicians is the lack of biomarkers to help develop a more accurate diagnosis, with the possibility of initiating the most effective treatment. The detection of biological markers for psychosis has the potential to contribute to improvements in its diagnosis, prognosis and treatment effectiveness. The mixture of multiple biomarkers may improve the ability to differentiate and classify these patients. In this sense, the aim of this study was to analyze the literature concerning the potential biomarkers that could be used in medical practice and to review the newest developments in electrochemical sensors used for dopamine detection, one of the most important exploited biomarkers.
\end{abstract}

\section{Contents}

1. Introduction

2. Scope of the review

Correspondence to: Dr Luana Geza, Discipline of Psychiatry, Neurosciences Department, 'Carol Davila' University of Medicine and Pharmacy, 37 Dionisie Lupu, 020021 Bucharest, Romania E-mail: geza.luana@gmail.com

Key words: immunology, psychosis, schizophrenia, dopamine, electrochemical sensor, voltammetry
3. Research methods

4. Results

5. General discussion

6. Conclusions

\section{Introduction}

Psychosis consists of a clinical disorder reflecting evident cognitive and perceptual function disturbances that are influenced, in most situations, by dysfunction of neurotransmission of dopamine and glutamate. Since the discovery of dopamine (3-hydroxytyramine) (DA), this catecholaminergic neurotransmitter has been of great interest to scientists due to its strong link to various diseases such as psychotic disorders, Parkinson's disease, Huntington's disease and addiction disorders. It was concluded that the symptoms of psychosis are caused by an increased activity of mesolimbic dopaminergic projections, leading to hyperstimulation of striatal dopaminergic D2 receptors (1).

Associated gene variants found in large-scale genetic analyses are reported to contribute to the risk of psychosis. Epidemiological research also suggests that there are numerous environmental causes of psychosis. Regardless of the etiology of the disorder, most patients may experience changes in function/structure of the brain, or alterations in neurophysiological parameters (2-4).

Biomarkers refer to a broad subgroup of biological signs, which are objective and can be measured accurately and reliably in a patient (5). Finding standardized biomarkers is an important concern of scientists in modern medicine. Their usefulness applies not only in establishing the diagnosis, but also in dividing patients into risk groups and establishing treatment and prognosis. For several years, the search for biomarkers for psychotic disorders has been continuous, but a non-invasive blood-based test that could be used for diagnostic or prognostic purposes remains uncertain (6). Many analytical techniques such as electrochemical techniques, especially 
voltammetry [cyclic (CV), differential pulse (DPV) and square wave (SWV)] at different electrochemical sensors have been used to develop new methods for the determination of specific biomarkers in different psychiatric and neurological diseases, successful results being obtained $(7,8)$.

Given the above information, in the attempt to discover biomarkers useful in clinical practice for the diagnosis of psychotic disorders, researchers have focused on developing methods for quantifying dopamine and its metabolites.

\section{Scope of the review}

The most frequently used methods to diagnose psychotic disorders on a regular basis are clinical tools that include psychiatric interviews, questionnaires and anamnestic data, as well as laboratory analysis of specific biomarkers. Therefore, the aim of this study was to present actualities in immunological markers and electrochemical sensors for the determination of dopamine and its metabolites levels in biological samples useful for holistic diagnosis of psychotic disorders.

\section{Research methods}

We researched electronic databases such as Pubmed, Google Scholar, Science Direct, Wiley, Springer and Web of Science for publications referring to immunological markers and electrochemical sensors for dopamine determination. In order to obtain a broad perspective about the subject, we included cumulatively a total of 90 scientific publications, only written in English and published between 1990 to 2021. Due to the importance of the topic, the number of articles regarding the electrochemical sensors for dopamine analysis published in the literature is very high. Therefore, in this review we included reviews from the end of 2020 and the papers (9) published in the first three months of 2021. For a better understanding of the subject, we included scientific publications containing the terms 'immunology', 'psychosis', 'dopamine', 'electrochemical sensors', 'voltammetry'.

\section{Results}

Immunological biomarkers. For years, the role of the immune system in the pathophysiology of psychosis has been a controversial issue, with both supporting and opposing proof from a multitude of different disciplines and research approaches, including epidemiology, pharmacology, cell and animal modeling, neuroimaging and biochemical analysis (10).

Only $40 \%$ of patients with schizophrenia show evidence of inflammatory activity transposed through interleukins such as IL-6, IL-1B,IL-8 and $\alpha$-1-antichymotrypsin transcript changes. These results are similar with the proportion of subjects with schizophrenia who exhibit brain abnormalities $(11,12)$.

In studies where brain microglia were analyzed, a substantial growth in $\left({ }^{11} \mathrm{C}\right)$ PK-11195 binding was found, suggesting a relation between brain inflammation and psychotic symptoms $(13,14)$.

An increase in the mean relative and absolute monocyte number in the peripheral circulation was described in individuals with non-affective psychosis (15). Patients with paranoid schizophrenia presented lower T cell numbers before treatment with normalized values over time after recovery (16).

IL-10, IL-6, tumor necrosis factor (TNF)- $\alpha$, antagonist receptor of IL-1 and soluble tumor necrosis factor receptor-1 (sTNFR1) were found to be elevated during mania in affective psychosis, demonstrating reliable activation of the inflammatory immune system (17-19). Different studies have evaluated the peripheral cytokines as state [IL-1 $\beta$, IL- 6 and transforming growth factor (TGF)- $\beta$ ] trait (IL-12, IFN- $\gamma$, TNF- $\alpha$ and sIL-2R) markers, in correlation with their dynamic in the acute episode of psychosis (20).

Peripheral immunologic blood cells from patients suffering from psychosis show modification not only with respect to their number, but also regarding their function such as the abnormal response to mitogenic stimulation in association with smoking $(21,22)$.

Proteomics. The term comprises the entire set of proteins that a biological system produces (23). It is a useful tool in the study of pathologies with complex etiology such as psychotic disorders (24). The most frequently studied biological product, from a proteomic point of view, is cerebrospinal fluid (CSF) (25).

Studies have shown the presence of the following biomarkers in CSF from the patients diagnosed with schizophrenia: Fibronectin 1 (FN1) (9), glutathione peroxidase 1 (GPX1) $(26,27)$, chromogranin A (CHGA) $(28,29)$, immunoglobulin superfamily member 8 (IGSF8) (30), microtubule-associated protein 2 (MAP2) $(31,32)$, neurofascin (NFASC) (33), heat shock protein 12A (HSP12A) (34) and protein tyrosine phosphatase receptor type Z1 (PTPRZ1) (35). In addition, in these patients, the expression of proteins such as apolipoprotein E (APOE), apolipoprotein A1 (APOA1) and prostaglandin D2 (PGD2) was observed, which led to the confirmation of the hypothesis that patients with schizophrenia have metabolic alterations such as dyslipidemia (36-38). PGD2 is also an important component in the arachidonic acid pathway and has been previously correlated with psychotic pathology (39).

Studies analyzing the proteomic profile of peripheral markers of patients with bipolar affective disorder and psychotic symptoms, found a different expression of a number of 36 proteins, but after additional tests, only two proteins, LIM and SH3 domain protein1 have been shown to be altered in bipolar disorder with psychotic elements (40).

Due to the availability and greater ease of collection, peripheral blood is an important biological product for the detailed study of biomarkers in various pathologies (41).

Studies that have analyzed peripheral blood proteomics have established a correlation between IL-1ra and IL-10 and antipsychotic treatment, showing decreased levels during therapy while improving symptoms (42).

Neurotransmitter biomarkers. Catecholamines play an important role in the organism and the general adaptation syndrome as neurotransmitters. Their concentration in various biological fluids is used as an indicator to determine a wide range of diseases. Due to their neurotransmitter functions in the brain, the concentration of catecholamines in body fluids can serve as a biochemical indicator for various mental 
disorders and for their pharmacological treatment. In this direction, great progress has been made in establishing the etiopathology of different neurotransmitters (43-45).

In the serum from patients with psychosis, multiple dopaminergic function biomarkers have been evaluated (43). Studies have demonstrated a correlation between dopamine uptake by platelets and the delusional state of patients with psychosis $(22,46,47)$.

The enzyme required for the synthesis of dopamine, tyrosine hydroxylase (TH), may be an important marker in psychotic disorders. One study concluded that the TH levels were abnormal in schizophrenia, whereas the levels of mRNA expression were not impacted, indicating that $\mathrm{TH}$ pathology may take place post-transcriptionally in this area (44). In addition, elevated levels of TH in lymphocytes of schizophrenia patients have been reported (45).

Homovanillic acid (HVA) is the main metabolite of dopamine; therefore, it may be a valuable biomarker for the diagnosis and prognosis of psychotic disorders. Elevated levels of HVA in plasma or CFS samples of patients with schizophrenia have been observed (48-50). Increased HVA levels in prodromal-phase patients may help the early diagnosis of schizophrenia (51).

In post-mortem human brains, as well as in the peripheral blood cells of schizophrenia patients, hypomethylation of the catechol-O-methyltransferase (COMT) gene promoter, leading to overexpression of COMT, was found $(52,53)$.

The absorption of ${ }^{18} \mathrm{~F}$-DOPA in the striatum of both drug-naive and drug-free schizophrenia patients was found to be increased compared to healthy participants, as shown by most research (54). Regarding the D2 dopaminergic receptors in striatum, a study conducted by Abi-Dargham et al did not find any difference between healthy subjects and a schizophrenia group (55).

While functional magnetic resonance imaging (fMRI) studies have found alterations in prefrontal and striatal dopaminergic projection fields, neurochemical research has shown subcortical striatal dysregulation of dopaminergic neurotransmission in psychotic patients (56).

Levels of norepinephrine (NEP) were found to be lower in psychotic patients, while epinephrine levels were similar in schizophrenic patients and a control group (57). Elevated levels of norepinephrine metabolite 3-methoxy-4-hydroxyphenylglycol (MHPG) have been noted in the plasma of psychotic patients, but not in CSF (58).

The most commonly reported scientific proof of serotoninergic system implication in psychosis was a reduction in the density of the 5-HT transporter (5-HTT), an improvement in the 5-HTR1A number and a decrease in 5-HTR2 levels in the brain (59). Elevated platelet 5-HT concentrations were ascertained in psychotic manic patients, while the manic patients without psychotic features group had platelet 5-HT levels similar to the values in a healthy control group (60).

Neuroendocrine biomarkers. For determination of the implication of the HPA (hypothalamic/pituitary/adrenal) axis in psychosis, the most investigated paraclinical test that supports this theory is the dexamethasone suppression test. In one study, significant elevated plasma cortisol levels in psychotic patients were determined (61). Some studies suggest that prolonged dexamethasone non-suppression is correlated with a poor outcome of the disorder (62).

Regarding cortisol levels in psychotic patients, a meta-analysis of patients at first episode of psychosis covering 23 studies emphasized increased plasma cortisol concentrations in patients with psychotic symptoms, compared to healthy control groups (63).

One study concerning the testosterone levels from saliva in teenager patients with prodromal symptoms of psychosis found that the concentrations of testosterone are higher in healthy controls $(64,65)$.

Electrochemical sensors for dopamine analysis. Electrochemical sensors are devices that transduce rapidly the information associated with the analyte/biomarker redox reaction that takes place at the electrode-solution interface into a measureable electrical signal, which can be easily exploited for the qualitative and quantitative analysis of the target compound (66). Due to their additional advantages such as the possibilities of miniaturization and of operating in both static and flow conditions, they are valuable candidates for the point-of-care $(\mathrm{PoC})$ detection of various biologically important analytes. Due to the high importance of neurotransmitters and of the even increasing necessity of simple, sensitive and selective methods for their accurate and rapid quantification in biological samples and/or pharmaceuticals, the literature contains a tremendous number of reports (hundreds of articles only in 2020) related to the electrochemical detection of dopamine (DA) using various bare or modified sensors. There are also recent reviews that have focused on molecularly imprinted polymers (67) and metal-organic framework (68) modified electrodes for catecholamine neurotransmitters detection, sensors and biosensors for DA determination (69), whereas the most recent one presents a critical discussion on the state-of-the-art advanced analytical techniques applied for in vivo tonic DA assessment in humans, special attention being paid to electrochemical techniques (70). Therefore, we will briefly discuss only the electrodes and the corresponding methods developed for DA analysis reported in the first months of 2021 .

Due to its high electrical conductivity and electrocatalytic properties, graphene, a two-dimensional carbon allotropic form, and its derivatives attracted even more interest and applicability as a sensing electrode material. Butler et al (71) demonstrated that commercially available graphene ink can be used for sensitive and selective DA detection after a thermal annealing process. Without the need of microfabrication processes, they developed a patterned three-electrode (with graphite ink electrode as the sensing part) all-solution processable platform on a flexible polyimide substrate which could be used in PoC testing.

One of the most sensitive DA electrochemical sensor is a carbon nanotube (CNT)-implanted polymer micropillar arrays electrode with the sensing part of CNTs exposed to the sample and the rest of it embedded in the sensor base, assuring the electrical conduction. DA quantification at this sensor presented two linear ranges $1 \times 10^{-9}-6 \times 10^{-8}$ mol $\times$ liter $^{-1}$ and $6 \times 10^{-8}-1 \times 10^{-6}$ mol $\times 1$ liter $^{-1}$ and a limit of detection of $7.7 \times 10^{-10}$ mol x $\operatorname{liter}^{-1}$ DA (72). 
Table I. Electrochemical sensors for DA quantification reported recently (in 2021) in the literature and their performance characteristics.

\begin{tabular}{|c|c|c|c|c|c|}
\hline Sensor & $\begin{array}{l}\text { Biomarker/ } \\
\text { analyte }\end{array}$ & $\begin{array}{l}\text { Linear range } \\
\left(\mathrm{mol} \mathrm{x} \mathrm{liter}^{-1}\right)\end{array}$ & $\begin{array}{c}\text { LoD } \\
\left(\text { mol x liter }^{-1}\right)\end{array}$ & Sample & (Refs.) \\
\hline BDDE & DA & $5.0 \times 10^{-7}-2.0 \times 10^{-6}$ & $6.0 \times 10^{-8}$ & In vitro measurements & (73) \\
\hline $\mathrm{Nb}_{2} \mathrm{C} / \mathrm{ZnS} / \mathrm{CGE}$ & DA & $9.0 \times 10^{-5}-8.2 \times 10^{-4}$ & $1.4 \times 10^{-6}$ & & (74) \\
\hline ZIF/GCE & DA & $2.5 \times 10^{-7}-5.9 \times 10^{-4}$ & $1.2 \times 10^{-8}$ & Injections, urine & (75) \\
\hline $\mathrm{NiO} / \mathrm{NiCo}_{2} \mathrm{O}_{4} / \mathrm{GCE}$ & DA & $1.0 \times 10^{-7}-1.0 \times 10^{-4}$ & $4.0 \times 10^{-8}$ & Injections, urine, serum & (76) \\
\hline $\mathrm{LaMnO}_{3} \mathrm{NPs} / \mathrm{GCE}$ & & $1.0 \times 10^{-6}-6.0 \times 10^{-4}$ & $3.2 \times 10^{-8}$ & Urine, saliva & (77) \\
\hline SiTi/AuNPs/CPE & $\begin{array}{l}\text { DA } \\
\text { NEP }\end{array}$ & $2.0 \times 10^{-5}-1.8 \times 10^{-4}$ & $\begin{array}{l}3.2 \times 10^{-7} \\
1.9 \times 10^{-7}\end{array}$ & Synthetic urine, saliva & (78) \\
\hline $\mathrm{CPC} / \alpha-\mathrm{ZrP} / \mathrm{GCE}$ & $\begin{array}{l}\text { DA } \\
\text { AA }\end{array}$ & $\begin{array}{l}1.3 \times 10^{-5}-5.2 \times 10^{-4} \\
4.0 \times 10^{-5}-1.5 \times 10^{-3}\end{array}$ & $\begin{array}{l}3.3 \times 10^{-6} \\
1.0 \times 10^{-5}\end{array}$ & Urine & (79) \\
\hline GA/YVO/SPCE & DA & $9.0 \times 10^{-9}-8.3 \times 10^{-6}$ & $1.5 \times 10^{-9}$ & Serum & (80) \\
\hline G/GQDs/GCE & DA & $1.0 \times 10^{-7}-1.0 \times 10^{-4}$ & $3.0 \times 10^{-8}$ & & (81) \\
\hline $\mathrm{GO} / \mathrm{WO}_{3} / \mathrm{GCE}$ & DA & $3 \times 10^{-7}-1.245 \times 10^{-3}$ & $3.06 \times 10^{-7}$ & Urine, tap water & (82) \\
\hline Ag@CQDs-rGO/GCE & DA & $1.0 \times 10^{-7}-3.0 \times 10^{-4}$ & $1.59 \times 10^{-9}$ & Injections, bovine serum & (83) \\
\hline G/SWCNT/Ce-Cu-Tween-20 & $\begin{array}{l}\text { DA } \\
\text { UA } \\
\text { Glu }\end{array}$ & $\begin{array}{l}1.0 \times 10^{-7}-1.0 \times 10^{-4} \\
8.0 \times 10^{-8}-1.0 \times 10^{-4} \\
1.0 \times 10^{-6}-1.0 \times 10^{-3}\end{array}$ & $\begin{array}{l}7.2 \times 10^{-9} \\
6.3 \times 10^{-9} \\
9.5 \times 10^{-8}\end{array}$ & Blood serum & (84) \\
\hline MWCNT-NH ${ }_{2} / \mathrm{AuNPs} / \mathrm{GCE}$ & $\begin{array}{l}\text { DA } \\
\text { UA }\end{array}$ & $\begin{array}{l}7.0 \times 10^{-7}-1.1 \times 10^{-4} \\
9.7 \times 10^{-7}-2.0 \times 10^{-4}\end{array}$ & $\begin{array}{l}2.1 \times 10^{-7} \\
2.9 \times 10^{-7}\end{array}$ & Urine & (85) \\
\hline PPy/TA/CTAB/SPCE & DA & $5.0 \times 10^{-7}-1.0 \times 10^{-4}$ & $2.9 \times 10^{-7}$ & & (86) \\
\hline $\mathrm{PANI} / \mathrm{H} / \mathrm{rGO}$ & $\begin{array}{l}\text { DA } \\
\text { UA } \\
\text { AA }\end{array}$ & $\begin{array}{l}5.0 \times 10^{-5}-3.5 \times 10^{-4} \\
1.0 \times 10^{-4}-7.0 \times 10^{-4} \\
1.0 \times 10^{-4}-7.0 \times 10^{-4}\end{array}$ & $\begin{array}{l}2.0 \times 10^{-8} \\
7.0 \times 10^{-8} \\
5.0 \times 10^{-8}\end{array}$ & & (87) \\
\hline MWCNT/oxCAP/GCE & $\begin{array}{l}\text { DA } \\
\text { UA } \\
\text { AA } \\
\text { XA } \\
\text { EP }\end{array}$ & $\begin{array}{c}5 \times 10^{-6}-1.15 \times 10^{-4} \\
5.0 \times 10^{-6}-7.0 \times 10^{-6} \\
5.0 \times 10^{-6}-7.5 \times 10^{-5} \\
1.0 \times 10^{-5}-9.5 \times 10^{-5} \\
5 \times 10^{-5}-1.15 \times 10^{-3}\end{array}$ & $\begin{array}{r}1.8 \times 10^{-6} \\
1.56 \times 10^{-6} \\
1.95 \times 10^{-6} \\
8.76 \times 10^{-6} \\
7.2 \times 10^{-6}\end{array}$ & $\begin{array}{l}\text { Injections } \\
\text { Synthetic blood plasma } \\
\text { Synthetic urine } \\
\text { Injections }\end{array}$ & (88) \\
\hline POA@Ag/GCE & DA & $5.0 \times 10^{-6}-4.5 \times 10^{-5}$ & $8.3 \times 10^{-7}$ & Hitections & (89) \\
\hline $\mathrm{PET} / \mathrm{GCE}$ & $\begin{array}{l}\text { DA } \\
\mathrm{PA}\end{array}$ & $\begin{array}{l}1.0 \times 10^{-7}-6.0 \times 10^{-5} \\
1.0 \times 10^{-7}-1.8 \times 10^{-4}\end{array}$ & $\begin{array}{r}7 \times 10^{-9} \\
1.8 \times 10^{-8}\end{array}$ & Pharmaceuticals & (90) \\
\hline
\end{tabular}

$\mathrm{GCE}$, glassy carbon electrode; BDDE, boron doped diamond electrode; $\mathrm{Nb}_{2} \mathrm{C} / \mathrm{ZnS} / \mathrm{CGE}$, niobium carbide-zinc sulfide nanocomposite modified GCE; ZIF/GCE, zeolite imidazolate framework modified GCE; $\mathrm{NiO} / \mathrm{NiCo}_{2} \mathrm{O}_{4} / \mathrm{GCE}$, nickel oxide-mixt nickel cobalt oxide nanocomposite modified GCE; $\mathrm{LaMnO}_{3}$, perovskite nanoparticles modified GCE; SiTi/AuNPs/CPE, silica/titania material incorporating gold nanoparticles modified GCE; CPC/ $\alpha$-ZrP/GCE, cetylpyridinium chloride/ $\alpha$-zirconium phosphate nanocomposite modified GCE; GA/YVO/SPCE, graphene aerogel-yttrium vanadate nanocomposite modified screen printed carbon electrode; G/GQDs/GCE, graphene-graphene quantum dots modified GCE; GO/ $/ \mathrm{WO}_{3} / \mathrm{GCE}$, graphene oxide-tungsten trioxide modified GCE; Ag@CQDs-rGO/GCE, polysaccharide-based carbon quantum dots-silver nanoparticles-graphene oxide modified GCE; G/SWCNT/Ce-Cu-Tween-20, graphene-single-walled carbon nanotubes-copper and cerium bimetallic nanoparticles modified GCE in the presence of the nonionic surfactant Tween-20; $\mathrm{MWCNT}_{-} \mathrm{NH}_{2} /$ AuNPs/GCE, aminofunctionalized multiwalled carbon nanotubes-gold nanoparticles modified GCE; PPy/TA/CTAB/SPCE, polypyrrole/tannin/cetyltrimethylammonium bromide/screen printed carbon electrode; PANI/H/rGO, polyaniline/hemin/reduced graphite oxide modified GCE; MWCNT/oxCAP/GCE, multiwalled carbon nanotubes-oxidized capsaicin modified GCE; POA@Ag/GCE, poly(o-aniside)-silver nanoparticles nanocomposite modified GCE; PET/GCE, polyethionine modified GCE; DA, dopamine; NEP, norepinephrine; AA, ascorbic acid; UA, uric acid; Glu, glucose; XA, xanthurenic acid; EP, epinephrine; PA, paracetamol; LoD, limit of detection.

The performance characteristics of other recently reported electrochemical sensors for DA detection are summarized in Table I (73-90).

Using a sensor array consisting of gold electrodes unmodified and modified with cross-reactive films, i.e., the biopolymer chitosan and chitosan-CNTs, and two chemometric approaches (artificial neural network and a partial least squares regression), Shukla et al (91) predicted DA levels in undiluted and untreated urine samples, eliminating the effects of the main interfering redox species, norepinephrine (NEP) and uric acid (UA). The disadvantage of the systems is related to the electrode surface contamination during the analysis. 
Therefore, this system is designed for single use applications but recent studies emphasized the CNTs antifouling properties. This electrode's array could be miniaturized and integrated into a portable device, in order to be used for the in situ analysis of clinical samples, obtaining physiological information that may help to diagnose and monitor various diseases.

An enhanced enzyme-free $\mathrm{CV}$ detection of DA performed at a bare GCE, based on the intrinsic peroxidase-like activity of the $\mathrm{Fe}_{3} \mathrm{O}_{4} @ \mathrm{Au}$ nanoparticles, exhibited a linear range from $1 \times 10^{-5}$ to $1 \times 10^{-3}$ mol x liter $^{-1} \mathrm{DA}$, with a LoD of $0.0109 \mathrm{mg} \mathrm{x}$ liter $^{-1}$. The feasibility of the developed method was successfully tested by DA assessment in pork samples (92).

Based on the above mentioned examples, electrochemical sensors proved to be useful tools for the rapid and selective monitoring of neurotransmitter levels in various biological samples, generating actual values that could support a better diagnose and even the treatment of certain psychotic disorders improving the quality of life of these patients.

\section{General discussion}

Dopamine is the most investigated system of neurotransmitters in psychotic disorders. There is heterogeneity of dopaminergic dysfunction that can be limited to only a subset of patients with schizophrenia. Dopamine works closely with 5-HT, glutamate and other systems; therefore, changes in one of the systems closely affect the balance of the other systems (93).

Among the dopaminergic hypotheses that are listed in the etiology of schizophrenia, studies have shown that an increase in activity in the mesolimbic dopaminergic pathway leads to positive psychotic symptoms while a decrease in dopaminergic transmission in the mesocortical pathway causes negative symptoms (94). The dopaminergic hypothesis is also strengthened by the mechanism of action of antipsychotics. Typical antipsychotics have a mechanism of action based on the antagonism of dopaminergic receptors and increased affinity for D2 receptors, while atypical antipsychotics are inhibitors of postsynaptic serotoninergic 5-HT2A receptors, most having a mild ability to antagonize dopamine D2 receptors (95).

Dopamine is involved in the stress response, leading to relapses in patients with schizophrenia (96). In addition, changes in 5-HT activity are involved in suicide and impulsive behavior of psychotic patients $(97,98)$.

Biomarkers represent an important tool in medical practice. Their usefulness applies not only to the diagnosis, but also for dividing patients into risk groups and establishing treatment and prognosis. In the case of inflammatory biomarkers (IL-1B, IL-6, IL8 and $\alpha$-1-antychymotripsin), studies have shown a marked inflammatory response in patients with schizophrenia $(11,12)$. There is also a strong correlation between the values of TNF- $\alpha$ and the triggering of psychosis (17-19). Proteomics represents the study of proteins on a broad scale, including immunological proteins. The most frequently studied biological product, form a proteomic point of view, is CSF (22-24). Studies have shown that the most frequent biomarkers in CSF include FN1, GPX1, CHGA, IGSF8, MAP2, NFASC, HSP12A and PTPRZ1 (9,26-38).

\section{Conclusions}

Changes in the concentrations of the neurotransmitters involved in psychotic pathology may be present as alterations in the metabolites of major neurotransmitters implicated in their pathogenesis, such as the dopamine, serotonin and norepinephrine system. As a result, elevated HVA values have been observed in the prodromal phase of patients with schizophrenia, elevated serum MHPG levels in psychotic patients and decreased 5-HTT. Because of the significance of neurotransmitters in psychotic disorders and the growing need for quick, responsive, and selective methods for rapid quantification and higher accuracy in biological samples, the electrochemical identification of dopamine (DA) using various bare or modified sensors has been investigated.

Many findings in sensor design have been made in research laboratories, resulting in a wealth of knowledge on the development of sensitive electrochemical sensors, for selective (no interference from commonly co-existing redox species such as AA and UA) and precise DA quantification, but simple to operate and reusable or single-use yet cost-effective. Proper sensor characterization, which includes determining the analytical performances, and then correlating these with electrode material properties, is as critical as the constant use of new materials in sensor construction. Sensitive electrochemical sensors have been shown to be effective instruments for the rapid monitoring of dopamine and its metabolite levels in various biological samples, advantages that could help improving the diagnosis, prognosis and even the treatment of psychotic disorders.

\section{Acknowledgements}

Not applicable.

\section{Funding}

No funding was received.

\section{Availability of data and materials}

All information in this review is documented by relevant references.

\section{Authors' contributions}

AMC contributed in all the stages of the article and gave the final approval of the version to be published. LG was involved in the writing, reviewing and editing of the manuscript. IGD, DEP and MB were responsible for analysis and interpretation of the literature data and contributed to drafting of the manuscript and revising it critically for important scientific content. AAC and LD were involved in revising the review critically for important intellectual content. All authors read and approved the final manuscript for publication.

\section{Ethics approval and consent to participate}

Not applicable. 


\section{Patient consent for publication}

Not applicable.

\section{Competing interests}

The authors declare that they have no competing interests.

\section{Authors' information}

Adela Magdalena Ciobanu: ORCID: ID0000-0003-2520-5486.

\section{References}

1. Lieberman JA and First MB: Psychotic disorders. N Engl J Med 379: 270-280, 2018.

2. Zwicker A, Denovan-Wright EM and Uher R: Gene-environment interplay in the etiology of psychosis. Psychol Med 48: 1925-1936, 2018.

3. Tsuang MT, BarJL, Stone WS and Faraone SV: Gene-environment interactions in mental disorders. World Psychiatry 3: 73-83, 2004.

4. Bell V, Wilkinson S, Greco M, Hendrie C, Mills B and Deeley Q: What is the functional/organic distinction actually doing in psychiatry and neurology? Wellcome Open Res 5: 138, 2020.

5. Strimbu K and Tavel JA: What are biomarkers? Curr Opin HIV AIDS 5: 463-466, 2010.

6. Domenici E, Willé DR, Tozzi F, Prokopenko I, Miller S, McKeown A, Brittain C, Rujescu D, Giegling I, Turck CW, et al: Plasma protein biomarkers for depression and schizophrenia by multi analyte profiling of case-control collections. PLoS One 5 : e9166, 2010.

7. Rabinca AA, Buleandra M, Tache F, Mihailciuc C, Ciobanu AM, Stefanescu DC and Ciucu AA: Voltammetric method for simultaneous determination of L-Dopa and Benserazide. Curr Anal Chem 13: 218-224, 2017.

8. Patrascu DG, David V, Balan I, Ciobanu AM, David IG, Lazar P, Ciurea I, Stamatin I and Ciucu AA: Selective DPV method of dopamine determination in biological samples containing ascorbic acid. Anal Lett 43: 1100-1110, 2010

9. Purves-Tyson TD, Robinson K, Brown AM, Boerrigter D, Cai HQ, Weissleder C, Owens SJ, Rothmond DA and Shannon Weickert C: Increased macrophages and C1qA, C3, C4 transcripts in the midbrain of people with schizophrenia. Front Immunol 11: 2002, 2020.

10. Birnbaum R and Weinberger DR: A genetics perspective on the role of the (Neuro)Immune system in schizophrenia. Schizophr Res 217: 105-113, 2020.

11. Herron JW, Nerurkar L and Cavanagh J: Neuroimmune biomarkers in mental Illness. Curr Top Behav Neurosci 40 45-78, 2018.

12. Fillman SG, Cloonan N, Catts VS, Miller LC, Wong J, McCrossin T, Cairns $\mathrm{M}$ and Weickert CS: Increased inflammatory markers identified in the dorsolateral prefrontal cortex of individuals with schizophrenia. Mol Psychiatry 18: 206-214, 2013.

13. Doorduin J, de Vries EF, Willemsen AT, de Groot JC, Dierckx RA and Klein HC: Neuroinflammation in schizophrenia-related psychosis: A PET study. J Nucl Med 50: 1801-1807, 2009.

14. Kurumaji A, Wakai T and Toru M: Decreases in peripheral-type benzodiazepine receptors in postmortem brains of chronic schizophrenics. J Neural Transm 104: 1361-1370, 1997.

15. Bergink V, Gibney SM and Drexhage HA: Autoimmunity, inflammation, and psychosis: A search for peripheral markers. Biol Psychiatry 75: 324-331, 2014.

16. Maino K, Gruber R, Riedel M, Seitz N, Schwarz M and Müller N: $\mathrm{T}$ - and B-lymphocytes in patients with schizophrenia in acute psychotic episode and the course of the treatment. Psychiatry Res 152: 173-180, 2007

17. Modabbernia A, Taslimi S, Brietzke E and Ashrafi M: Cytokine alterations in bipolar disorder: A meta-analysis of 30 studies. Biol Psychiatry 74: 15-25, 2013.

18. Goldstein BI, Kemp DE, Soczynska JK and McIntyre RS: Inflammation and the phenomenology, pathophysiology, comorbidity, and treatment of bipolar disorder: A systematic review of the literature. J Clin Psychiatry 70: 1078-1090, 2009.
19. Hope S, Dieset I, Agartz I, Steen NE, Ueland T, Melle I, Aukrust P and Andreassen OA: Affective symptoms are associated with markers of inflammation and immune activation in bipolar disorders but not in schizophrenia. J Psychiatr Res 45: 1608-1616, 2011.

20. Miller BJ, Buckley P, Seabolt W, Mellor A and Kirkpatrick B: Meta-analysis of cytokine alterations in schizophrenia: Clinical status and antipsychotic effects. Biol Psychiatry 70: 663-671, 2011.

21. Craddock RM, Lockstone HE, Rider DA, Wayland MT, Harris LJ, McKenna PJ and Bahn S: Altered T-cell function in schizophrenia: A cellular model to investigate molecular disease mechanisms. PLoS One 2: e692, 2007.

22. Dean B, Kulkarni J, Copolov DL, Shrikanthan P, Malone V and Hill C: Dopamine uptake by platelets from subjects with schizophrenia: A correlation with the delusional state of the patient. Psychiatry Res 41: 17-24, 1992.

23. Wilkins MR, Sanchez JC, Gooley AA, Appel RD, Humphery-Smith I, Hochstrasser DF and Williams KL: Progress with proteome projects: Why all proteins expressed by a genome should be identified and how to do it. Biotechnol Genet Eng Rev 13: 19-50, 1996.

24. Martins-de-Souza D, Guest PC, Rahmoune H and Bahn S: Proteomic approaches to unravel the complexity of schizophrenia. Expert Rev Proteomics 9: 97-108, 2012.

25. Huang JT, Leweke FM, Oxley D, Wang L, Harris N, Koethe D, Gerth CW, Nolden BM, Gross S, Schreiber D, et al: Disease biomarkers in cerebrospinal fluid of patients with first-onset psychosis. PLoS Med 3: e428, 2006.

26. Shao X, Yan C, Sun D, Fu C, Tian C, Duan L and Zhu G: Association between glutathione peroxidase-1 (Gpx-1) polymorphisms and schizophrenia in the Chinese han population. Neuropsychiatr Dis Treat 16: 2297-2305, 2020.

27. Tran TV, Dang DK, Tran HQ, Shin EJ, Jang CG, Yamada K, NabeshimaTandKimHC:PM377.Role of glutathioneperoxidase-1 gene in the phencyclidine-induced schizophrenia-like psychosis in mice. Int J Neuropsychopharmacol 19: 38, 2016.

28. van Kammen DP, Peters J, Yao J, Neylan T, Beuger M, Pontius E and O'Connor DT: CSF chromogranin A-like immunoreactivity in schizophrenia. Assessment of clinical and biochemical relationships. Schizophr Res 6: 31-39, 1991.

29. Takahashi N, Ishihara R, Saito S, Maemo N, Aoyama N, Ji X, Miura H, Ikeda M, Iwata N, Suzuki T, et al: Association between chromogranin A gene polymorphism and schizophrenia in the Japanese population. Schizophr Res 83: 179-183, 2006.

30. Lee SA and Huang KC: Epigenetic profiling of human brain differential DNA methylation networks in schizophrenia. BMC Med Genomics 9: 68, 2016.

31. Anderson SA, Volk DW and Lewis DA: Increased density of microtubule associated protein 2-immunoreactive neurons in the prefrontal white matter of schizophrenic subjects. Schizophr Res 19: 111-119, 1996.

32. Law AJ, Weickert CS, Hyde TM, Kleinman JE and Harrison PJ: Reduced spinophilin but not microtubule-associated protein 2 expression in the hippocampal formation in schizophrenia and mood disorders: Molecular evidence for a pathology of dendritic spines. Am J Psychiatry 161: 1848-1855, 2004.

33. Farkas N, Lendeckel U, Dobrowolny H, Funke S, Steiner J, Keilhoff G, Schmitt A, Bogerts B and Bernstein HG: Reduced density of ADAM 12-immunoreactive oligodendrocytes in the anterior cingulate white matter of patients with schizophrenia. World J Biol Psychiatry 11: 556-566, 2010.

34. Pongrac JL, Middleton FA, Peng L, Lewis DA, Levitt P and Mirnics K: Heat shock protein 12A shows reduced expression in the prefrontal cortex of subjects with schizophrenia. Biol Psychiatry 56: 943-950, 2004.

35. Buxbaum JD, Georgieva L, Young JJ, Plescia C, Kajiwara Y, Jiang Y, Moskvina V, Norton N, Peirce T, Williams H, et al: Molecular dissection of NRG1-ERBB4 signaling implicates PTPRZ1 as a potential schizophrenia susceptibility gene. Mol Psychiatry 13: 162-172, 2008.

36. Huang JT, Wang L, Prabakaran S, Wengenroth M, Lockstone HE, Koethe D, Gerth CW, Gross S, Schreiber D, Lilley K, et al: Independent protein-profiling studies show a decrease in apolipoprotein A1 levels in schizophrenia CSF, brain and peripheral tissues. Mol Psychiatry 13: 1118-1128, 2008.

37. Boiko AS, Mednova IA, Kornetova EG, Semke AV, Bokhan NA, Loonen AJM and Ivanova SA: Apolipoprotein serum levels related to metabolic syndrome in patients with schizophrenia. Heliyon 5: e02033, 2019. 
38. Famitafreshi $\mathrm{H}$ and Karimian $\mathrm{M}$ : Prostaglandins as the agents that modulate the course of brain disorders. Degener Neurol Neuromuscul Dis 10: 1-13, 2020.

39. Condray R and Yao JK: Cognition, dopamine and bioactive lipids in schizophrenia. Front Biosci (Schol Ed) 3: 298-330, 2011.

40. Giusti L, Mantua V, Da Valle Y, Ciregia F, Ventroni T, Orsolini G, Donadio E, Giannaccini G, Mauri M, Cassano GB and Lucacchini A: Search for peripheral biomarkers in patients affected by acutely psychotic bipolar disorder: A proteomic approach. Mol Biosyst 10: 1246-1254, 2014.

41. Franceschini A, Szklarczyk D, Frankild S, Kuhn M, Simonovic M, Roth A, Lin J, Minguez P, Bork P, von Mering C and Jensen LJ: STRING v9.1: Protein-protein interaction networks, with increased coverage and integration. Nucleic Acids Res 41 (Database Issue): D808-D815, 2013

42. de Witte L, Tomasik J, Schwarz E, Guest PC, Rahmoune H, Kahn RS and Bahn S: Cytokine alterations in first-episode schizophrenia patients before and after antipsychotic treatment Schizophr Res 154: 23-29, 2014.

43. Buttarelli FR, Fanciulli A, Pellicano C and Pontieri FE: The dopaminergic system in peripheral blood lymphocytes: From physiology to pharmacology and potential applications to neuropsychiatric disorders. Curr Neuropharmacol 9: 278-288, 2011.

44. Perez-Costas E, Melendez-Ferro M, Rice MW, Conley RR and Roberts RC: Dopamine pathology in schizophrenia: Analysis of total and phosphorylated tyrosine hydroxylase in the substantia nigra. Front Psychiatry 3: 31, 2012.

45. Liu L, Jia F, Yuan G, Chen Z, Yao J, Li H and Fang C: Tyrosine hydroxylase, interleukin-1beta and tumor necrosis factor-alpha are overexpressed in peripheral blood mononuclear cells from schizophrenia patients as determined by semi-quantitative analysis. Psychiatry Res 176: 1-7, 2010.

46. Kessler A and Shinitzky M: Platelets from schizophrenic patients bear autoimmune antibodies that inhibit dopamine uptake. Psychobiology 21: 299-306, 1993.

47. Rabey JM, Lerner A, Sigal M, Graff E and Oberman Z: [3H] dopamine uptake by platelet storage granules in schizophrenia. Life Sci 50: 65-72, 1992.

48. Arrúe A, Dávila R, Zumárraga $\mathrm{M}$, Basterreche $\mathrm{N}$ González-Torres MA, Goienetxea B, Zamalloa MI, Anguiano JB and Guimón J: GABA and homovanillic acid in the plasma of Schizophrenic and bipolar I patients. Neurochem Res 35: 247-253, 2010

49. Luykx JJ, Bakker SC, Lentjes E, Neeleman M, Strengman E, Mentink L, DeYoung J, de Jong S, Sul JH, Eskin E, et al: Genome-wide association study of monoamine metabolite levels in human cerebrospinal fluid. Mol Psychiatry 19: 228-234, 2014.

50. Baeza I, Castro-Fornieles J, Deulofeu R, de la Serna E, Goti J, Salvà $\mathrm{J}$ and Bernardo $\mathrm{M}$ : Plasma homovanillic acid differences in clinical subgroups of first episode schizophrenic patients Psychiatry Res 168: 110-118, 2009.

51. Sumiyoshi T, Kurachi M, Kurokawa K, Yotsutsuji T, Uehara T, Itoh $\mathrm{H}$ and Saitoh O: Plasma homovanillic acid in the prodromal phase of schizophrenia. Biol Psychiatry 47: 428-433, 2000.

52. Abdolmaleky HM, Cheng KH, Faraone SV, Wilcox M, Glatt SJ, Gao F, Smith CL, Shafa R, Aeali B, Carnevale J, et al: Hypomethylation of MB-COMT promoter is a major risk factor for schizophrenia and bipolar disorder. Hum Mol Genet 15 3132-3145, 2006

53. Melas PA, Rogdaki M, Ösby U, Schalling M, Lavebratt C and Ekström TJ: Epigenetic aberrations in leukocytes of patients with schizophrenia: Association of global DNA methylation with antipsychotic drug treatment and disease onset. FASEB J 26: $2712-2718,2012$

54. Cao T, Li N and Cai H: Candidate metabolic biomarkers for schizophrenia in CNS and periphery: Do any possible associations exist? Schizophr Res 226: 95-110, 2020

55. Abi-Dargham A, Gil R, Krystal J, Baldwin RM, Seibyl JP, Bowers M, van Dyck CH, Charney DS, Innis RB and Laruelle M: Increased striatal dopamine transmission in schizophrenia: Confirmation in a second cohort. Am J Psychiatry 155: 761-767, 1998.

56. Winton-Brown TT, Fusar-Poli P, Ungless MA and Howes OD: Dopaminergic basis of salience dysregulation in psychosis. Trends Neurosci 37: 85-94, 2014

57. Catak Z, Kocdemir E, Ugur K, Yardim M, Sahin İ, Kaya H and Aydin S: A novel biomarker renalase and its relationship with its substrates in schizophrenia. J Med Biochem 38: 299-305, 2019.
58. Nagaoka S, Iwamoto $\mathrm{N}$ and Arai H: First-episode neuroleptic-free schizophrenics: Concentrations of monoamines and their metabolites in plasma and their correlations with clinical responses to haloperidol treatment. Biol Psychiatry 41: 857-864, 1997.

59. Abi-Dargham A: Alterations of serotonin transmission in schizophrenia. Int Rev Neurobiol 78: 133-164, 2007.

60. Sagud M, Mihaljevic-Peles A, Pivac N, Jakovljevic M and Muck-Seler D: Platelet serotonin and serum lipids in psychotic mania. J Affect Disord 97: 247-251, 2007.

61. Altamura C, Guercetti G and Percudani M: Dexamethasone suppression test in positive and negative schizophrenia. Psychiatry Res 30: 69-75, 1989.

62. Tandon R, Mazzara C, DeQuardo J, Craig KA Meador-Woodruff JH, Goldman R and Greden JF: Dexamethasone suppression test in schizophrenia: Relationship to symptomatology, ventricular enlargement, and outcome. Biol Psychiatry 29: 953-964, 1991

63. Hubbard DB and Miller BJ: Meta-analysis of blood cortisol levels in individuals with first-episode psychosis. Psychoneuroendocrinology 104: 269-275, 2019.

64. van Rijn S, Aleman A, de Sonneville L, Sprong M, Ziermans T, Schothorst P, van Engeland $\mathrm{H}$ and Swaab H: Neuroendocrine markers of high risk for psychosis: Salivary testosterone in adolescent boys with prodromal symptoms. Psychol Med 41: 1815-1822, 2011

65. Lodha P and Karia S: Testosterone and Schizophrenia: A clinical review. Ann Indian Psychiatry 3: 92-96, 2019.

66. Shetti NP, Nayak DS, Reddy KR and Aminabhvi TM: Graphene Clay-based hybrid nanostructures for electrochemical sensors and biosensors. In: Graphene-Based Electrochemical Sensors for Biomolecules. Pandikumar A and Rameshkumar (eds.) Elsevier, New York, pp235-274, 2019.

67. Elugoke SE, Adekunle SA, Fayemi OE, Akpan ED, Mamba BB El-Sayed MS and Ebenso EE: Molecularly imprinted polymers (MIPs) based electrochemical sensors for the determination of catecholamine neurotransmitters-Review. Electrochem Sci Adv 1: e2000026, 2021.

68. Gao LL and Gao EQ: Metal-organic frameworks for electrochemical sensors of neurotransmitters. Coord Chem Rev 434: 213784, 2021

69. Liu X and Liu Y: Biosensors and sensors for dopamine detection. VIEW 2: 20200102, 2021.

70. Rusheen AE, Gee TA, Jang DP, Blaha CD, Bennet KE, Lee KH, Heien ML and Oh Y: Evaluation of electrochemical methods for tonic dopamine detection in vivo. Trends Analyt Chem 132: 116049,2020

71. Butler D, Moore D, Glavin NR, Robinson JA and Ebrahimi A: Facile Post-deposition annealing of graphene ink enables ultrasensitive electrochemical detection of dopamine. ACS Appl Mater Interfaces 13: 11185-11194, 2021.

72. Chang AY, Liu X, Pei Y, Gong C, Arumugam PU and Wang S: Dopamine sensing with robust carbon nanotube implanted polymer micropillar array electrodes fabricated by coupling micromolding and infiltration coating processes. Electrochim Acta 368: 137632, 2021.

73. Brycht M, Baluchová S, Taylor A, Mortet V, Sedláková S, Klimša L, Kopeček J and Schwarzová-Pecková K: Comparison of electrochemical performance of various boron-doped diamond electrodes: Dopamine sensing in biomimicking media used for cell cultivation. Bioelectrochemistry 137: 107646, 2021.

74. Arif N, Gul S, Sohail M, Rizwan S and Iqbal M: Synthesis and characterization of layered $\mathrm{Nb} 2 \mathrm{C}$ MXene/ZnS nanocomposites for highly selective electrochemical sensing of dopamine. Ceram Int 47: 2388-2396, 2021

75. Dong Y, Liu J and Zheng J: A sensitive dopamine electrochemical sensor based on hollow zeolitic imidazolate framework. Colloids Surf A Physicochem Eng Asp 608: 125617, 2021.

76. Amiri M, Javar HA and Mahmoudi-Moghaddam H: Facile green synthesis of $\mathrm{NiO} / \mathrm{NiCo} 2 \mathrm{O} 4$ nanocomposite as an efficient electrochemical platform for determination of dopamine. Electroanalysis 33: 1205-1214, 2021.

77. Shafi PM, Joseph N, Karthik R, Shim JJ, Bose AC and Ganesh V: Lemon juice-assisted synthesis of $\mathrm{LaMnO} 3$ perovskite nanoparticles for electrochemical detection of dopamine. Microchem J 164: 105945, 2021.

78. Morawski FM, Xavier BB, Virgili AH, Caetano KDS de Menezes EW, Benvenutti EV, Costa TMH and Arenas LT: A novel electrochemical platform based on mesoporous silica/titania and gold nanoparticles for simultaneous determination of norepinephrine and dopamine. Mater Sci Eng C Mater Biol Appl 120: 111646, 2021 
79. Liu L, Ge Y, Liu X, Ruan J, Cao J, Wei C, Fang P, Zhou J, Ma J and Tong Z: One-pot ball-milling preparation of cetylpyridinium chloride/azirconium phosphate composite for simultaneous detection of ascorbic acid and dopamine. J Alloys Compd 860: $157927,2021$.

80. Kokulnathan T, Ahmed F, Chen SM, Chen TW, Hasan PMZ, Bilgrami AL and Darwesh R: Rational confinement of yttrium vanadate within Three-dimensional graphene aerogel: Electrochemical analysis of monoamine neurotransmitter (Dopamine). ACS Appl Mater Interfaces 13: 10987-10995, 2021.

81. Tian $\mathrm{J}$ and $\mathrm{Wu} \mathrm{W}$ : A novel preparation of water-dispersed graphene and their application to electrochemical detection of dopamine. Adv Powder Technol 32: 619-629, 2021.

82. Anbumannan V,KumarRTR and Suresh K: Enhanced electrochemical detection of dopamine by graphene oxide/tungsten trioxide nanocomposite. Mater Sci Semicond Process 127: 105696, 2021.

83. Han G, Cai J, Liu C, Ren J, Wang X, Yang J and Wang X: Highly sensitive electrochemical sensor based on xylan-based Ag@ CQDs-rGO nanocomposite for dopamine detection. Appl Surf Sci 541: 148566, 2021.

84. Li R, Liang H, Zhu M, Lai M, Wang S, Zhang H, Ye H, Zhu R and Zhang W: Electrochemical dual signal sensing platform for the simultaneous determination of dopamine, uric acid and glucose based on copper and cerium bimetallic carbon nanocomposites Bioelectrochemistry 139: 107745, 2021

85. Guan Q, Guo H, Xue R, Wang M, Zhao X, Fan T, Yang W, Xu M and Yang W: Electrochemical sensor based on covalent organic frameworks-MWCNTNH2/AuNPs for simultaneous detection of dopamine and uric acid. J Electroanal Chem 880: 114932, 2021.

86. Abdi MM, Azli NFWM, Chaibakhsh N, Lim HN, Tahir PM, Karimi G and Khorram M: Nonenzymatic dopamine biosensor based on tannin nanocomposite. J Polym Sci 59: 428-438, 2021.

87. Aryal KP and Jeong HK: Simultaneous determination of ascorbic acid, dopamine, and uric acid with polyaniline/hemin/reduced graphite oxide composite. Chem Phys Lett 768: 138405, 2021.

88. Da Silva LV, dos Santos ND, de Almeida AKA dos Santos DDER, Santos ACF, França MC, Lima DJP, Lima PR and Goulart MOF: A new electrochemical sensor based on oxidized capsaicin/multi-walled carbon nanotubes/glassy carbon electrode for the quantification of dopamine, epinephrine, and xanthurenic, ascorbic and uric acids. J Electroanal Chem 881: $114919,2021$.
89. Paulraj P, Rajendran K, Sathamraja A and Kannaiyan P: Solid phase mechanochemical synthesis of Poly(o-anisidine) protected Silver nanoparticles for electrochemical dopamine sensor. Mater Today Commun 26: 102191, 2021.

90. Kannan A, Manojkumar S and Radhakrishnan S: A Facile Fabrication of Poly-ethionine Film on Glassy Carbon electrode for simultaneous and sensitive detection of dopamine and paracetamol. Electroanalysis 33: 1175-1184, 2021.

91. Shukla RP, Aroosh M, Matzafi A and Ben-Yoav H: Partially functional electrode modifications for rapid detection of dopamine in urine. Adv Funct Mater 31: 2004146, 2021.

92. Guan H, Liu B, Gong D, Peng B, Han B and Zhang N: Direct electrochemical enhanced detection of dopamine based on peroxidase-like activity of $\mathrm{Fe}_{3} \mathrm{O}_{4} @ \mathrm{Au}$ composite nanoparticles. Microchem J 164: 105943, 2021.

93. Howes O, McCutcheon R and Stone J: Glutamate and dopamine in schizophrenia: An update for the 21st century. J Psychopharmacol 29: 97-115, 2015

94. McCutcheon RA, Abi-Dargham A and Howes OD: Schizophrenia, dopamine and the striatum: From Biology to Symptoms. Trends Neurosci 42: 205-220, 2019.

95. Kaczor AA, Targowska-Duda KM, Silva AG, Kondej M, Biała G and Castro M: $N$-(2-Hydroxyphenyl)-1-(3-(2-oxo-2,3-dihydro- $1 H$ benzimidazol-1yl)propyl)piperidine-4-Carboxamide (D2AAK4), a Multi-target ligand of aminergic GPCRs, as a potential antipsychotic. Biomolecules 10: 349, 2020.

96. Bloomfield MAP, McCutcheon RA, Kempton M, Freeman TP and Howes O: The effects of psychosocial stress on dopaminergic function and the acute stress response. Elife 8: e46797, 2019.

97. Jacobsen JPR, Medvedev IO and Caron MG: The 5-HT deficiency theory of depression: Perspectives from a naturalistic 5-HT deficiency model, the tryptophan hydroxylase $2 \mathrm{Arg} 439 \mathrm{His}$ knockin mouse. Philos Trans R Soc Lond B Biol Sci 367: 2444-2459, 2012.

98. Ciobanu AM, Rosca T, Vladescu CT, Tihoan C, Popa MC, Boer MC and Cergan R: Frontal epidural empyema (Pott's puffy tumor) associated with Mycoplasma and depression. Rom J Morphol Embryol 55: 1203-1207, 2014.

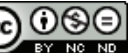

This work is licensed under a Creative Commons Attribution-NonCommercial-NoDerivatives 4.0 International (CC BY-NC-ND 4.0) License. 